\title{
Retraction Note to: Clinical significance of perineural invasion diagnosed by immunohistochemistry with anti-S100 antibody in Stage I-III colorectal cancer
}

\author{
Yoshifumi Shimada ${ }^{1} \cdot$ Tomoki Kido $^{1} \cdot$ Hitoshi Kameyama ${ }^{1} \cdot$ Mae Nakano $^{1} \cdot$ Ryoma Yagi $^{1} \cdot$ Yosuke Tajima $^{1}$. \\ Takuma Okamura ${ }^{1} \cdot$ Masato Nakano $^{1}$ - Masayuki Nagahashi ${ }^{1} \cdot$ Takashi Kobayashi $^{1} \cdot$ Masahiro Minagawa $^{1}$. \\ Shin-ichi Kosugi ${ }^{1} \cdot$ Toshifumi Wakai $^{1} \cdot$ Yoichi Ajioka $^{2}$
}

Published online: 6 February 2022

(c) The Author(s) under exclusive licence to Springer Nature Singapore Pte Ltd. 2022

\section{Retraction to:}

Surg Today (2015) 45:1493-1500 https://doi.org/10.1007/s00595-014-1096-9

The Editor-in-Chief has retracted this Article. The research presented was previously published in Japanese [1].

All authors have agreed to this retraction.

\section{Reference}

1. Kido T. Clinical significance of neural invasion identified by S-100 immunohistochemistry in patients with colon cancer. Niigata Med J. 2014;128:167-76.

Publisher's Note Springer Nature remains neutral with regard to jurisdictional claims in published maps and institutional affiliations.
The original article can be found online at https://doi.org/10.1007/ s00595-014-1096-9.

\section{Yoshifumi Shimada}

shimaday@med.niigata-u.ac.jp

1 Division of Digestive and General Surgery, Graduate School of Medical and Dental Sciences, Niigata University, 1-757 Asahimachi-dori, Niigata 951-8510, Japan

2 Division of Molecular and Diagnostic Pathology, Graduate School of Medical and Dental Sciences, Niigata University, 1-757 Asahimachi-dori, Niigata, Japan 